\title{
Justicia indígena y sus técnicas de procedimiento para sancionar a los infractores
}

\section{Indigenous justice and its procedural techniques for punishing offenders}

\author{
Rosa Leonor Maldonado-Manzo \\ ub.rosamaldonado@uniandes.edu.ec \\ Universidad Regional Autónoma de los Andes, Babahoyo \\ Ecuador \\ https://orcid.org/0000-0002-0083-3227 \\ Génesis Mercedes Peñafiel-Huerta \\ db.genesismph05@uniandes.edu.ec \\ Universidad Regional Autónoma de los Andes, Babahoyo \\ Ecuador \\ https://orcid.org/0000-0002-0162-5403 \\ Miluska Natasha Chasiluisa-Vera \\ db.miluskancv31@uniandes.edu.ec \\ Universidad Regional Autónoma de los Andes, Babahoyo \\ Ecuador \\ https://orcid.org/0000-0003-4012-2072 \\ Denisse Elizabeth Parrales-Hernández \\ db.denisseeph27@uniandes.edu.ec \\ Universidad Regional Autónoma de los Andes, Babahoyo \\ Ecuador \\ https://orcid.org/0000-0003-4321-006X
}

Recepción: 15 de septiembre 2021

Revisado: 25 octubre 2021

Aprobación: 15 de noviembre 2021

Publicación: 01 de diciembre 2021 


\section{Estimado Editor (a):}

Los integrantes de las comunidades indígenas que no estén de acuerdo con los procedimientos aplicados para los castigos estarían sufriendo una grave vulneración de sus derechos a la integridad e intimidad personal, así como a ser juzgados ante un tribunal en igualdad de condiciones donde prevalezca la presunción de inocencia, tal como se expresa en los instrumentos legales vigentes. En este sentido, la Constitución de la República del Ecuador (2008) establece:

Artículo 66 numeral 3. El derecho a la integridad personal incluye:

a) La integridad física, psíquica, moral y sexual.

b) Una vida libre de violencia en el ámbito público y privado. El Estado adoptará las medidas necesarias para prevenir, eliminar y sancionar toda forma de violencia, en especial la ejercida contra las mujeres, niñas, niños y adolescentes, personas adultas mayores, personas con discapacidad y contra toda persona en situación de desventaja o vulnerabilidad; idénticas medidas se tomarán contra la violencia, la esclavitud y la explotación sexual.

c) La prohibición de la tortura, la desaparición forzada y los tratos y penas crueles, inhumanas o degradantes.

d) La prohibición del uso de material genético y la experimentación científica que atenten contra los derechos humanos.

Por lo expuesto, es necesario concientizar a las personas que integran estas comunidades indígenas de Otavalo, para evitar que sus castigos sean extremistas como lo evidencia (Cevallos et al., 2017) en el caso de Sumak Warmi, y generen como consecuencia incluso la muerte de los ciudadanos como lo evidencia (Ocampo y Sánchez, 2016) además, de que se incentive a aplicar la plurinacionalidad, pero dentro de una perspectiva inclinada a compartir las tradiciones culturales y ancestrales fomentando el turismo, sin que se use este instrumento de reconocimiento plurinacional de forma negativa para adoptar sanciones inhumanas.

La Declaración Universal de Derechos Humanos en su artículo 10 enuncia que:

Toda persona tiene derecho, en condiciones de plena igualdad, a ser oída públicamente y con justicia por un tribunal independiente e imparcial, para la determinación de sus derechos y obligaciones o para el examen de cualquier acusación contra ella en materia penal. (Organización de las Naciones Unidas, 1969). 
Por otro lado, Ortiz, (2012) mencionan que los derechos en una comunidad indígena de Cotacachi, en tales circunstancias se efectuó el castigo comunitario o justicia indígena por adulterio a una joven mujer kichwa madre de cuatro niños llamada Sumak Warmi, cuyo objetivo es determinar los derechos vulnerados que en transcurso al debido procedimiento para sancionar o castigar las infracciones por medio del procedimiento ancestral de la justicia indígena.

La justicia indígena está garantizada en la Constitución del Ecuador (2008):

Artículo. 171.- Las autoridades de las comunidades, pueblos y nacionalidades indígenas ejercerán funciones jurisdiccionales, con base en sus tradiciones ancestrales y su derecho propio, dentro de su ámbito territorial, con garantía de participación y decisión de las mujeres. Las autoridades aplicarán normas y procedimientos propios para la solución de sus conflictos internos, y que no sean contrarios a la Constitución y a los derechos humanos reconocidos en instrumentos internacionales.

El Estado garantizará que las decisiones de la jurisdicción indígena sean respetadas por las instituciones y autoridades públicas. Dichas decisiones estarán sujetas al control de constitucionalidad. La ley establecerá los mecanismos de coordinación y cooperación entre la jurisdicción indígena y la jurisdicción ordinaria.

De acuerdo con el mencionado artículo que trata sobre las reglas y principios de la Justicia Indígena para su aplicabilidad, deja en manifiesto estricto que se debe basar fundamentalmente en los derechos, garantías y principios que atañen a cada ciudadano sea que este goce de fuero ordinario o pertenezca a las comunidades de nacionalidades indígenas, debiéndose de regir en los tratados e instrumentos internacionales sin vulnerabilidad de sus derechos propios que le son inherentes por ley. Por ello, el procedimiento penal indígena está sujeto de tradiciones organizadas, conforme a su estructura cultural, religiosas, económicas, raciales, idioma propio, ideología, costumbres ancestrales, conocimiento al entorno natural que hacen distribución plena de sus recursos naturales en beneficio del entorno social y la vida. En tan sentido, se considera que la justicia indígena es aplicada con base en las costumbres, tradiciones y los saberes ancestrales que por su misma historia se ha transformado en derecho consuetudinario, dichos conocimientos de la justicia. El 
indígena va transmitiendo de generación en generación siendo aplicados por la autoridad en el seno de la comunidad, por tal razón existe diferentes formas creando distintas representaciones de hacer justicia de acuerdo con cada comunidad siendo necesaria la implementación de una norma básica para los procedimientos. Por otro lado, las autoridades, de la comunidad desconocen de un debido proceso que debe seguir al momento de ejercer la justicia indígena, por ende, se vulneran derechos de las personas, se puede evidenciar que hay autoridades que desconocen la fundamentación jurídica de un acto siendo esta una gran debilidad que se demuestra en la justicia indígena, la aplicación de sanciones, dentro esta comunidad y de muchas comunidades, existe un abuso increíble al momento de aplicar la Justicia Indígena.

\section{FINANCIAMIENTO}

No monetario.

\section{AGRADECIMIENTO}

A la Universidad Regional Autónoma de los Andes, Babahoyo, por motivar el desarrollo de la Investigación.

\section{REFERENCIAS CONSULTADAS}

Asamblea Nacional Constituyente de la República del Ecuador, (2008). Constitución de la República del Ecuador. [Constitution of the Republic of Ecuador]. Montecristi. Registro Oficial 449 de 20-oct-2008. Recuperado de https://n9.cl/sia

Cevallos, R., Yépez, M., Suárez, I., y Flores, E. (2017). La justicia indígena en el marco de la violencia de género. [Indigenous justice in the context of gender-based violence]. Revista Ecuatoriana de Ciencias Sociales y Jurídicas, 2(2), 10-29. Recuperado de: $\underline{\text { https://n9.cl/429ir }}$

Ocampo, E., y Sánchez, A. (2016). La justicia indígena y el pluralismo jurídico en Ecuador.: El constitucionalismo en América Latina. [Indigenous Justice and Legal Pluralism in Ecuador: Constitutionalism in Latin America]. Derecho y Cambio Social, 13(44), 1. Recuperado de: https://n9.cl/ie1jh3 
Rosa Leonor Maldonado Manzo; Génesis Mercedes Peñafiel Huerta; Miluska Natasha Chasiluisa Vera; Denisse Elizabeth Parrales Hernández

Organización de las Naciones Unidas (1969). Declaración Universal de los Derechos Humanos. [Universal Declaration of Human Rights]. Nueva York: Naciones Unidas. Recuperado de: https://n9.cl/imy5

Ortiz, S. (2012). ¿Comuneros kichwas o ciudadanos ecuatorianos?: la ciudadanía étnica y los derechos políticos de los indígenas de Otavalo y Cotacachi, 19902009. [Kichwa communards or Ecuadorian citizens?: ethnic citizenship and the political rights of the indigenous people of Otavalo and Cotacachi, 1990-2009]. Flacso-Sede Ecuador. Recuperado de: https://n9.cl/axvki

(C2021 por los autores. Este artículo es de acceso abierto y distribuido según los términos y condiciones de la licencia Creative Commons Atribución-NoComercial-Compartirlgual 4.0 Internacional (CC BY-NC-SA 4.0) (https://creativecommons.org/licenses/by-nc-sa/4.0/). 